\title{
Flexibility in migratory strategy contrasts with reliance on restricted staging and overwintering grounds for Sabine's gulls from the Canadian High Arctic
}

https://doi.org/10.1515/ami-2020-0106

received March 23, 2021; accepted August 3, 2021
Keywords: Non-breeding; Movement ecology; Seabirds; Repeatability; Stopovers; Biologging; Tracking; Migration

\section{Introduction}

Birds undertake some of the most impressive migrations on the planet, often splitting their year between vastly different environments to take advantage of localized seasonal bursts of resources [1, 2]. Despite their remarkable mobility, most long-distance migrants typically need to alternate between bouts of continuous transit and bouts of rest or re-fueling at stopover or staging sites along the routes connecting their breeding and overwintering areas [3]. Many different spatial and temporal aspects of migration are controlled by relatively rigid endogenous mechanisms which ensure that individuals engage in specific activities at the appropriate time in the annual cycle [4-7]. Yet, some degree of individual behavioural flexibility in decision-making about migratory scheduling, routes, or when and where to make stops is advantageous as a means to respond to unpredictable or variable ecological conditions [4, 7-9]. A review of published data on individual repeatability in timing of spring migration for long-distance migratory birds revealed high variation among studies, suggesting that species and populations can vary widely due to true consistent individual phenological tendencies but also decisions made in response to environmental conditions encountered en route [7]. Yet, in a compilation of studies reporting changes (or lack of) in spatial migration patterns, all species with suboptimal routes were long-distance migrants [10], indicating that spatial components of migration may be under more strict control [11]. Assessing between and within-individual variation in migratory strategies is necessary before we 
can consider resilience to environmental change for populations and species of long-distance migrants.

Sabine's gulls (Xema sabini) undertake the longest migration of any Larid, a trans-equatorial journey from Arctic breeding areas to tropical wintering areas in the Southern hemisphere $[12,13]$. These gulls breed in small scattered colonies across a wide circumpolar range [14], but are known to winter in only two distinct areas south of the equator, one in the Atlantic off the coasts of Southern Africa and Namibia within the Benguela Current [12, 15], the other in the Pacific, off the northwestern coasts of South America within the Humboldt Current $[13,14]$. Migrating such great distances $(>15,000 \mathrm{~km})$ to access geographically restricted wintering sites is uncommon among gulls but is typical of other pelagic seabirds that migrate to continuously target distant areas of predictable upwelling and high marine productivity suited to their foraging strategies [16-19]. Gulls, on the other hand, are more typically characterized by their highly adaptable and opportunistic foraging tactics [20,21], and tend to be relatively short-distance migrants rarely exhibiting distinct staging behaviour en route $[22,23]$. The diet of Sabine's gulls outside the Arctic region during migration and overwinter is not well documented [14]; they are known to follow fishing boats, scavenge offal, and capture crustaceans and fishes, and also commonly feed on swarming surface zooplankton through surface-seizing and dipping, most often in groups, more akin to the foraging strategies of phalaropes and terns [14, 24]. Thus, it might be expected that Sabine's gulls would exhibit relatively high individual behavioural flexibility on their lengthy migration due to their generalist gull nature but may also target areas of high zooplankton availability along the way.

Using geolocator (GLS) devices, the migratory routes taken by Sabine's gulls between a Greenlandic colony and overwintering grounds in the Atlantic were described for the first time [12]. Interestingly, this work revealed consistent staging behaviour among tracked birds. On the way south, birds concentrated in the Bay of Biscay and Iberian seas off the coasts of France, Spain, and Portugal, staging for 45 days on average. On the return trip north, birds staged for 19 days on average, in a different area off the West African coast (Senegal, Mauritania, and Morocco). Subsequent GLS tracking work from a colony in the Canadian high Arctic discovered that some birds used the same general Atlantic routes and overwinter areas, while others migrated through the Pacific [13]. Before these two tracking studies, very little was known about the movement ecology of Sabine's gulls during the non-breeding period [14]. Further, few studies have evaluated individual repeatability in migratory behaviour in gulls or population-level consistency in the use of particular staging areas on migration (but see [4]), and this has not been investigated for Pacific migrating Sabine's gulls.

Descriptive tracking work suggests that Sabine's gulls may have limited behavioural flexibility during key stages of migration and overwinter [12, 13]. To further our relatively limited understanding of the non-breeding ecology of Sabine's gulls in the Pacific, we used both lower spatial resolution GLS and higher resolution satellite platform terminal transmitter (PTT) devices to track 22 birds, with some individuals tracked over multiple years, to accomplish two main objectives: 1) document for the first time in detail the complete round-trip migratory journey, and provide support from PTT data for both coastal and overland routes detected with GLS, and 2) quantify variation in migratory strategies with metrics representing spatiotemporal aspects of migration on both the southbound and northbound journeys. We evaluated flexibility in strategies among individuals, years, and sexes in terms of schedules, routes, and key stopping/staging areas. Our findings have important implications for the ability of Sabine's gulls to adjust their migratory behaviour in response to environmental change driven by anthropogenic influences.

\section{Methods}

\subsection{Device deployment and retrieval}

We conducted field research between early June and late August over six years between 2008-2017 on Nasaruvaalik Island, Nunavut $\left(75.8^{\circ} \mathrm{N}, 96.3^{\circ} \mathrm{W}\right.$; Fig. 1$)$, a small island in the Canadian High Arctic (described in [25]). Deployment and retrieval of GLS devices has been described in detail elsewhere [13]. In summary, we deployed GLS devices (LAT2900 or LAT2500, Lotek Wireless, Canada) on 33 adult breeding Sabine's gulls, 14 of which were equipped twice. In 2017, we deployed solar-powered PTT devices (Microwave Telemetry Inc.) on two birds that had previously been equipped with GLS. The 12-g PTT devices were attached to each bird with a teflon tube harness and positioned using a leg-loop design on the lower back anterior to the uropygial gland [26]. The sex of equipped birds was determined through analysis of blood collected from the brachial vein. 


\subsection{Data processing}

GLS data were first corrected using SST correlation in LAT Viewer Studio (Lotek Wireless, Canada) to improve the accuracy of latitude estimates (uncorrected with an average accuracy of $\sim 200 \mathrm{~km}$ [27]) and allowed for the retention of data around the equinoxes (as per [28]), providing a single position estimate per day (described in [13]). PTT data were filtered for duplicates (retained a single position of highest ARGOS location class quality when more than one fix was obtained within one hour) and interpolated to the same daily interval as the GLS data using the R package 'SDLfilter' [29]). Both GLS and PTT data were filtered to remove positions with unrealistic flight speeds (max speed of $13.9 \mathrm{~m} / \mathrm{s}$; [30]). We then used a discrete-time correlated random walk in the form of a hierarchical state-space model (SSM) to reduce location error and produce a single location estimate per day for both GLS and PTT data [31-34]. Models were run in R with TMB using modified code from [35]. For the objectives of this study, two birds that migrated to the Atlantic were not included in further analysis, including one of two PTTtracked birds (see [13] for discussion of Atlantic migrating Sabine’s gulls from Nasaruvaalik Island). Further, we

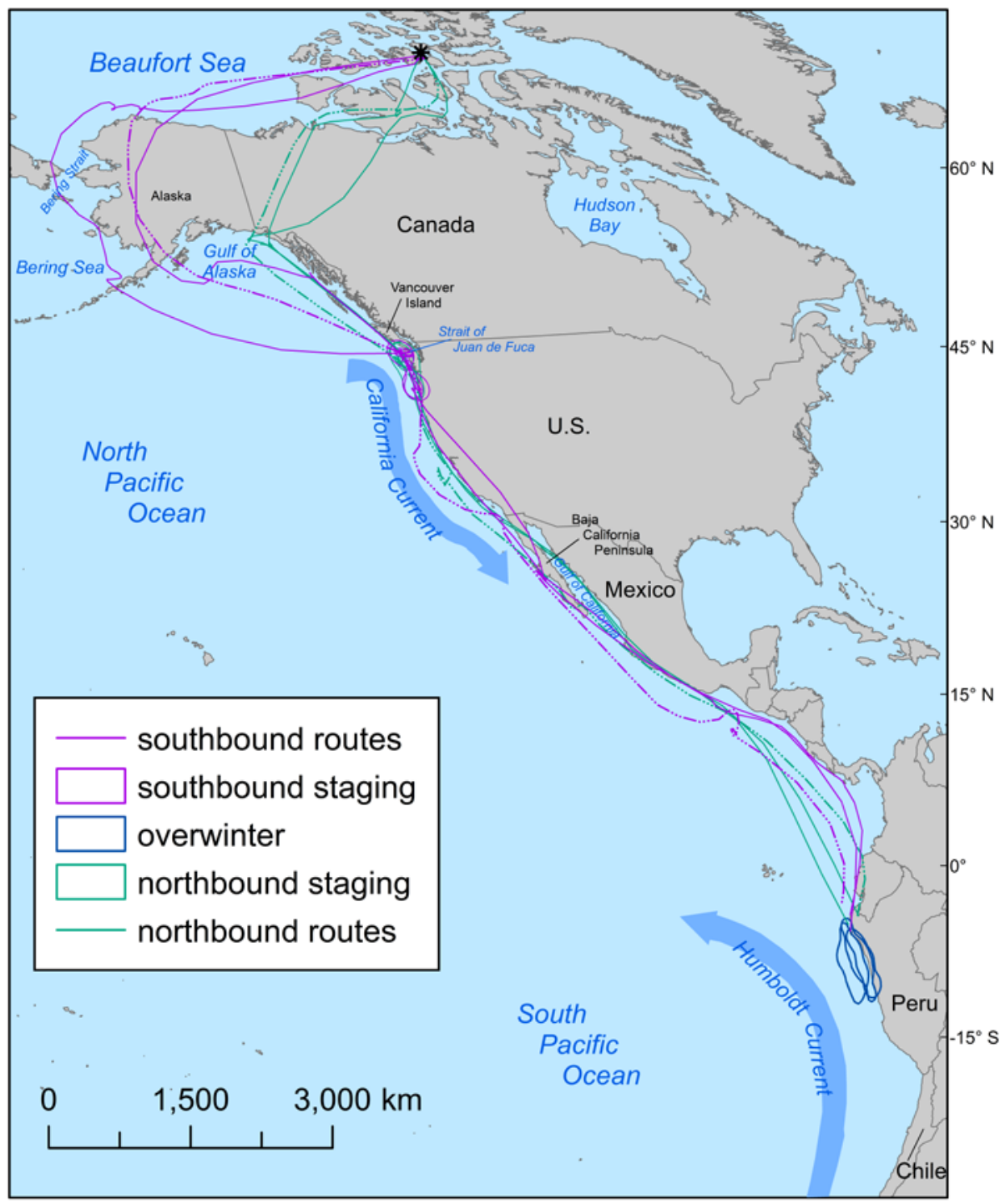

Figure 1: Overview of the study region with key geographic and oceanographic features. The high Arctic breeding colony at Nasaruvaalik Island, Nunavut, Canada is indicated with a black asterisk. Example migratory routes and staging/overwintering grounds are shown for a single individual Sabine's gull tracked through three complete non-breeding periods. Positional data were derived from a GLS device in 2011 (dashed lines) and a PTT device in 2017 and 2018 (solid lines). 
excluded data from devices that failed early, before a bird reached the major staging area on southbound migration (see below). Thus, the final data set of filtered and SSM-processed positions consisted of 22 birds tracked over 32 bird-years (unique bird-year combinations, where 'year' refers to the year of device deployment, i.e. 2008 refers to the 2008/09 non-breeding season, where birds depart the colony on southbound migration in Aug 2008 and return in Jun or Jul 2009). Thirteen individuals were GLS-tracked in a single year, eight individuals were GLS-tracked in two different years, and one individual was tracked in three different years (one year with a GLS and two years (2017 and 2018) with a PTT; Fig. 1). Processed tracking data are archived at Movebank (www.movebank.org).

\subsection{Describing migratory strategy}

Based on visual examination of tracks animated in Google Earth (Google Earth Pro v7.3.2.5776), the date of initiation of southbound migration was determined as the first day of colony departure without return. Each bird-year track was thus limited to positions from the start of southbound migration to the last position before device failure, or the first day of colony return on northbound migration, whichever came first. Along each bird-year track, we identified periods of distinct behavioural states of either 'transits' or 'stopovers' based on daily movement rates (i.e. minimum great-circle distances travelled per 24-h period) between positions, calculated using the R package 'move' with a Lambert Azimuthal Equal Area projection [17, 36, 37]. A clear breakpoint in a histogram of movement rates was identified at $125 \mathrm{~km} \mathrm{~d}^{-1}$; stopovers were differentiated from transits along a track as periods of $\geq 2 \mathrm{~d}$ with movement rates continuously $\leq 125 \mathrm{~km} \mathrm{~d}^{-1}$.

From the behaviourally-delineated tracks, the start and end of the overwinter stage was identified for each bird-year as the extended stopover period following arrival to the Humboldt Current off the Peruvian coast (Fig. 2). A consistent stopover area used by all birds on both southbound and northbound migration was also readily identifiable, where every bird-year stopped between $37^{\circ} \mathrm{N}$ and $51^{\circ} \mathrm{N}$ latitude along the Pacific coast of British Columbia, Canada, and Washington, Oregon, and California, U.S., within the California Current System (CCS; Fig. 1). This extended stopover is hereafter referred to as the 'staging' phase of either southbound or northbound migration, as the consistency and duration of these stopovers suggest birds are accessing abundant, predictable food resources in preparation for the energetic challenge of the next leg of the journey [3]. This staging period is thus used to further delineate each migratory direction into the pre-staging, staging, and post-staging phase.

Migratory strategy is described in relation to metrics representing phenological, movement, and spatial aspects of migration. Migration metrics were computed by migratory phase, representing southbound and northbound migration (further split into pre-staging, staging, post-staging), and overwinter. Phase-specific metrics were only calculated for bird-years with tracks representing a complete phase. Phenological metrics capture the migratory schedule of each bird-year, described as calendar dates related to each phase. Movement metrics include phase durations, transit distances travelled (excluding stopover days), and number of stopovers and number of days spent in stopovers. Spatial metrics describe comparisons of areas used on the staging and overwintering grounds and of route locations in each transit phase. We generated phase-specific individual kernel density estimates (KDE) with the 'adehabitatHR' package [38] using positions from southbound staging, overwinter, or northbound staging for bird-years with respective completed phases. We used a smoothing parameter of two and a $2^{\circ} \times 2^{\circ}$ grid cell size, based on the mean accuracy of the GLS devices [39]. We took the $75 \%$ kernel density estimate contour (75\% KDE) as representative of the main area used by each bird in a given year and phase, reducing the effect of outlier positions on polygon shape and size while still capturing the core area used. We then computed the degree of overlap of $75 \% \mathrm{KDE}$ among each unique bird-year:bird-year combination in each phase using the 'kerneloverlap' function, creating a dataset of pairwise comparison values that ranged from 0 (no overlap) to 1 (complete overlap; [40]). Using the same bird-year:bird-year combinations, route locations for each transit phase were compared by calculating intertrack distances based on nearest neighbour analysis [41, 42]. For each position in a focal track phase, we calculated the great-circle distance to the nearest position estimate in the paired track using the package 'nabor'. We then quantified the median intertrack distance for each pair. Again, comparisons were only made between pairs where both bird-years had completed a given phase, resulting for example in a maximum of 496 comparisons between 32 bird-years during southbound pre-staging and a minimum of 45 comparisons between 10 bird-years during northbound post-staging.

\subsection{Statistical analysis}

We first used linear mixed-effect models ( $R$ package 'Ime4'; [43]) to evaluate the effects of sex $(n=10$ males, 
$n=12$ females) and year on phenological and movement migration metrics, with individual bird ID included as a random intercept. The 'ImerTest' package [44] was used to calculate $p$-values. Where significant year effects were detected, Welch's $t$-tests or Mann-Whitney-Wilcoxon tests (when variables differed from normal distributions) were used to evaluate differences in metrics between the two years with sample sizes greater than two $(2010 n=16,2011$ $n=12$ ), as well as between phases of southbound and northbound migratory stages.

We then assessed individual repeatability as a statistical proxy for behavioural consistency (or conversely, flexibility) in migration metrics, as repeatable or consistent behaviours show relatively low within-individual variance compared to high among-individual variance $[19,39,45]$. We calculated repeatability $(R)$ in migratory traits obtained in different years for the same individuals based on the intra-class correlation coefficient from linear mixed-effect models fitted with bird ID as a random intercept using the package 'rptR' v. 0.9.21 [46]. Because initial evaluations found significant effects of year on some metrics (but not sex), year was included as a fixed effect and we report either repeatability or adjusted repeatability where appropriate, corresponding standard error, and $p$-values. Due to the small sample size of individuals repeatedly tracked through the entire overwinter period and northbound migration, repeatability was only evaluated for 11 southbound migration metrics and overwinter start date.

For spatial migration metrics where pairwise comparisons were computed, we used a linear mixed-effect model with the binary fixed factors 'same sex', 'same year', and 'same bird', and individual bird ID as a random intercept to test for differences among and within groups in the spatial overlaps of staging and overwinter distributions (pair-wise proportion of overlap of individual 75\% KDE) and southbound and northbound migratory routes before and after staging (pair-wise median intertrack distances between routes of each phase). All values are presented as the mean \pm SD unless otherwise stated.

\section{Results}

We tracked 22 birds over 32 bird-years, with tracking durations of 62 to $332 \mathrm{~d}$ (mean $216 \pm 95 \mathrm{~d}$ ). Sample sizes thus varied across the seven distinct migratory phases (Table 1); tracking captured completed southbound pre-staging and southbound staging phases for all birds and bird- years, and complete return migrations for 8 birds and 10 bird-years.

\subsection{Migration in detail}

Birds departed the colony on southbound migration within a 30-d window in late Jul through Aug (Table 1), heading due west toward the Beaufort Sea (Fig. 2). Routes then diverged into two strategies: 1) Birds travelled through the Bering Strait making stopovers mostly at islands and coastlines in Alaska; or, 2) Birds made a direct transit inland across the Alaska interior without stopping (Fig. 2). On average, birds made less than 2 stopovers totalling $5 \pm 7$ $\mathrm{d}$ during the southbound pre-staging phase (Table 1). Few birds made stops beyond the Alaska panhandle, instead travelling directly to the major staging grounds around Vancouver Island, British Columbia (B.C.), Canada and south along the Pacific coast of the United States (U.S.; Fig. 2). Travel rates averaged $192 \mathrm{~km} \mathrm{~d}^{-1}$ on transit days during the pre-staging phase, covering $c .5200 \mathrm{~km}$ (Table 1). The duration of southbound staging was variable but birds spent $28 \pm 12 \mathrm{~d}$ in Aug/Sep (Table 1) before continuing southbound migration. In the post-staging phase, average transit travel rates were $220 \mathrm{~km} \mathrm{~d}^{-1}$ with stopovers occurring throughout the $c .7700 \mathrm{~km}$ transited to reach the overwinter grounds between mid-Oct and early Dec (Table 1, Fig. 2).

After spending c. 5 months in the relatively restricted range of the overwinter grounds off the coast of Peru and Chile (Fig. 2), birds departed on northbound migration in Mar/Apr. Overall, northbound migration was significantly shorter than southbound $\left(t_{34}=5.21, p<0.001\right.$, mean difference $22 \mathrm{~d}$ ), driven by shorter northbound than southbound staging ( $W=390, p<0.001$, mean difference $18 \mathrm{~d}$ ) while durations of transitory phases of each stage were not significantly different (southbound pre-staging vs. northbound post-staging: $W=195, p>0.05$; southbound post-staging vs. northbound pre-staging: $W=180.5, p$ $>0.05$, Table 1). Because southbound and northbound staging occurred in the same region (Fig. 2), the potential minimum distance travelled between the overwinter and staging grounds are identical. Similar routes were taken during both phases, and there was no significant difference between duration or distance travelled (duration: $W$ $=180, p>0.05$; distance: $W=197, p>0.05$; Table 1, Fig. 1). The number of stops and number of days spent on stops was similar with c. $12 \mathrm{~d}$ spent on 2-3 stopovers, however the location of stopovers differed. On southbound post-staging, stopovers occurred all along routes while on northbound pre-staging, all birds travelled nearly constantly 
Table 1: Migratory traits of Sabine’s gulls tracked from the breeding colony in the Canadian high Arctic over five different years.

\begin{tabular}{|c|c|c|c|}
\hline & $\mathrm{n}$ birds/n bird-yrs & mean \pm SD & Min - Max \\
\hline \multicolumn{4}{|l|}{ Schedules } \\
\hline southbound migration departure & $22 / 32$ & 11 Aug $\pm 8 d$ & 29 Jul - 27 Aug \\
\hline southbound staging arrival & $22 / 32$ & $08 \mathrm{Sep} \pm 11 \mathrm{~d}$ & 21 Aug - 30 Sep \\
\hline overwinter arrival & $19 / 26$ & $12 \mathrm{Nov} \pm 15 \mathrm{~d}$ & 17 Oct - 7 Dec \\
\hline overwinter departure & $12 / 14$ & $10 \mathrm{Apr} \pm 9 \mathrm{~d}$ & $28 \mathrm{Mar}-24 \mathrm{Apr}$ \\
\hline northbound staging arrival & $12 / 14$ & 15 May $\pm 7 \mathrm{~d}$ & 30 Apr - 25 May \\
\hline northbound colony arrival & $8 / 10$ & 20 Jun $\pm 8 d$ & 10 Jun - 13 Jul \\
\hline \multicolumn{4}{|l|}{ Durations } \\
\hline southbound migration & $19 / 26$ & $91 \pm 19 \mathrm{~d}$ & $61-129$ \\
\hline pre-staging phase & $22 / 32$ & $27 \pm 9 d$ & $13-55$ \\
\hline staging phase & $22 / 32$ & $28 \pm 12 \mathrm{~d}$ & $4-54$ \\
\hline post-staging phase & $19 / 26$ & $35 \pm 13 d$ & $18-66$ \\
\hline overwinter & $12 / 14$ & $147 \pm 16 \mathrm{~d}$ & $122-179$ \\
\hline northbound migration & $8 / 10$ & $69 \pm 7 d$ & $61-82$ \\
\hline pre-staging phase & $12 / 14$ & $33 \pm 7 d$ & $23-44$ \\
\hline staging phase & $11 / 13$ & $10 \pm 4 d$ & $4-19$ \\
\hline post-staging phase & $8 / 10$ & $25 \pm 9 d$ & $19-48$ \\
\hline \multicolumn{4}{|l|}{ Transit distances } \\
\hline southbound pre-staging & $32 / 22$ & $5198 \pm 1075 \mathrm{~km}$ & $3644-7842$ \\
\hline southbound post-staging & $19 / 26$ & $7721 \pm 758 \mathrm{~km}$ & $6778-10199$ \\
\hline northbound pre-staging & $12 / 14$ & $7558 \pm 739 \mathrm{~km}$ & $5969-8775$ \\
\hline northbound post-staging & $8 / 10$ & $4305 \pm 410 \mathrm{~km}$ & $3795-4987$ \\
\hline \multicolumn{4}{|l|}{ Stopover numbers and days } \\
\hline southbound pre-staging no. & $22 / 32$ & $1.3 \pm 1.3$ & $0-5$ \\
\hline southbound pre-staging days & $22 / 32$ & $5 \pm 7 d$ & $0-26$ \\
\hline southbound post-staging no. & $19 / 26$ & $2.5 \pm 1.4$ & $0-5$ \\
\hline southbound post-staging days & $19 / 26$ & $12 \pm 10 \mathrm{~d}$ & $0-37$ \\
\hline northbound pre-staging no. & $12 / 14$ & $2.3 \pm 0.8$ & $1-3$ \\
\hline northbound pre-staging days & $12 / 14$ & $12 \pm 6 d$ & $4-22$ \\
\hline northbound post-staging no. & $8 / 10$ & $2.9 \pm 1$ & $2-5$ \\
\hline northbound post-staging days & $8 / 10$ & $13+/-9 d$ & $4-35$ \\
\hline
\end{tabular}

until reaching the Baja California Peninsula, where all 12 birds (in 14 bird-years) made stops either off the west coast of the peninsula or within the Gulf of California. These stops lasted 3-20 d ( $9 \pm 6$ d) in early-Apr to mid-May, after which birds continued north making stops along the U.S west coast before reaching the staging grounds (Fig. 2).

The potential minimum distance travelled between the staging grounds and the colony during the northbound post-staging and southbound pre-staging phase was equal. However, because routes taken on these northbound and southbound phases differed markedly (Fig. 2), significantly shorter distances were travelled on northbound post-staging than southbound pre-staging ( $W$ $=241, p<0.01$, maximum median distance between two routes $1343 \mathrm{~km})$. More stops were taken $\left(t_{51}=-3.58, p<0.001\right.$, mean difference 1.6 stops) and more days were spent on stops $\left(t_{43}=-3.02, p<0.01\right.$, mean difference $8 \mathrm{~d}$ ) along the route on northbound post-staging than southbound pre-staging (Table 1, Fig. 2). Two northbound migration strategies during the post-staging phase were apparent: 1) Birds moved from the staging grounds directly to the Gulf of Alaska where following a stopover, birds took direct, north or northeast overland routes transiting between 1100 to $1600 \mathrm{~km}$ in 4 to $5 \mathrm{~d}$. Most birds made stopovers again after passing the coast before returning to the colony (Fig. 2). Or, 2) Following staging, birds transited eastward overland, direct to Hudson Bay. One bird slowed for 3 days in central Saskatchewan, but these overland trips were otherwise direct and covered c. $2400 \mathrm{~km}$ in c. $10 \mathrm{~d}$. 


\subsection{Year-to-year flexibility in migratory strategy}

There was a significant effect of year on the colony departure date for southbound migration $\left(13.1 \pm 4.8 \mathrm{~d} \mathrm{SE}, t_{27}=\right.$ $-2.7, p=0.01$ ), and the total distance travelled during the southbound pre-staging phase of migration (1756 \pm 695 $\left.\mathrm{km} \mathrm{SE}, t_{27}=2.5, p=0.02\right)$. Comparing the two years with sample sizes greater than two ( $2010 n=16$ vs. $2011 n=12)$, in 2010 birds departed the colony on average 7 days earlier than in 2011 ( $W=37.5, p<0.01$; 2010: 08 Aug \pm 7 d, 2011: $15 \mathrm{Aug} \pm 5 \mathrm{~d})$ and took routes on average $989 \mathrm{~km}$ longer between the colony and the staging grounds ( $W=148, p$ < 0.01; 2010: $5660 \pm 1128 \mathrm{~km}, 2011: 4671 \pm 654 \mathrm{~km})$. This difference appears to be driven by most birds electing to travel through the Bering Strait in 2010, while overland

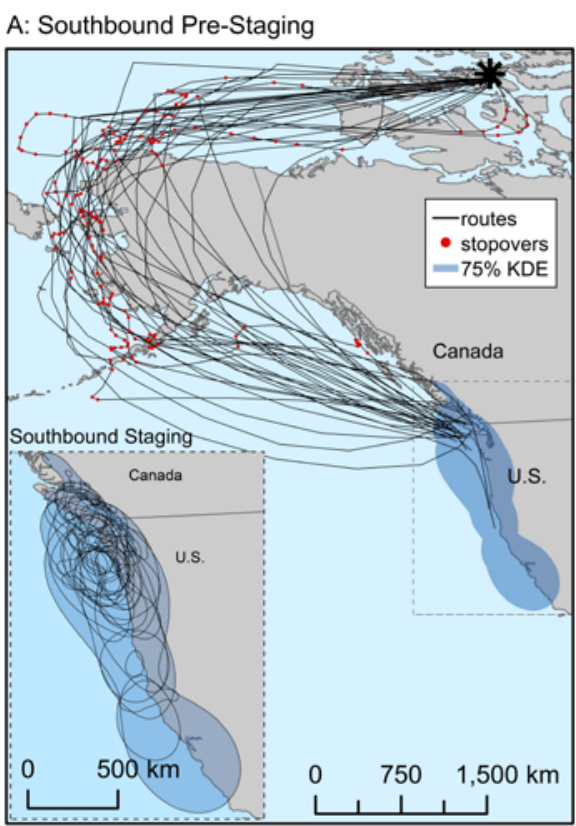

B: Southbound Post-Staging

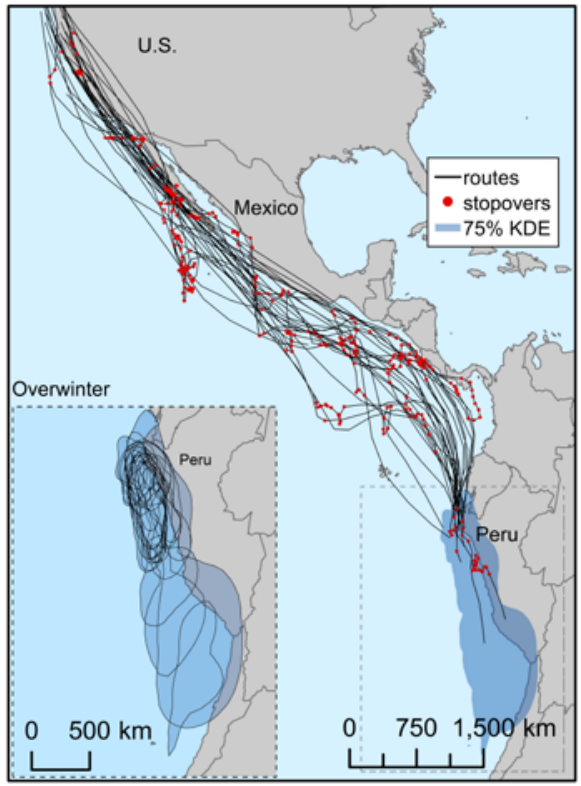

C: Northbound Pre-Staging

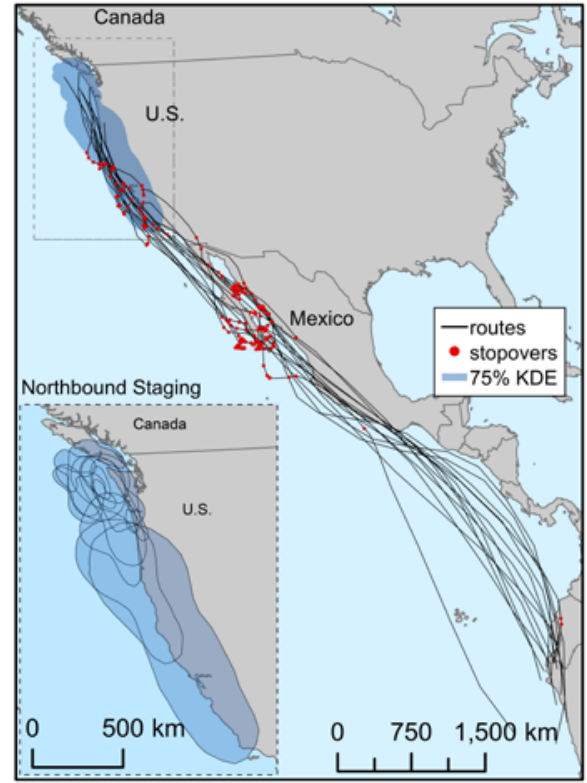

D: Northbound Post-Staging

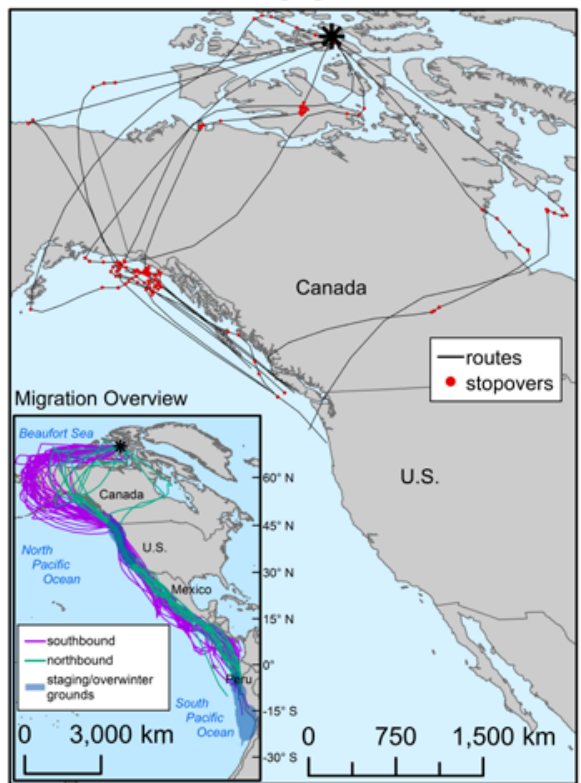

Figure 2: Trans-equatorial return migration of Sabine's gulls from the high Arctic breeding colony at Nasaruvaalik Island, Nunavut (black asterisk). Each pane depicts routes with stopover locations by migratory phase (sample sizes in Table 1 ). A-C insets show overlap of individual $75 \%$ kernel density estimates (KDE) for staging and overwinter grounds. D inset shows overview of the study area and all tracking data from 22 birds over 32 bird-years (Winkel-Tripel projection). 
routes in 2011 crossed over Alaska from the Beaufort Sea (Fig. 3). The median intertrack distance during the southbound post-staging phase of migration was significantly smaller within the same year than among different years $\left(-25.3 \pm 10.7 \mathrm{~km} \mathrm{SE}, t_{317}=-2.35, p<0.05\right)$. Most birds in all years followed a similar nearshore, coastal route from the staging grounds until passing the southern tip of the Baja California Peninsula, but then diverged in strategy for the remainder of the phase (Fig. 2). In 2010, five birds took considerable pelagic detours while in 2011 (as well as
2008, 2017 and 2018), most birds took comparatively direct and similar routes off the west coast of Mexico and central America to arrive to the overwintering grounds (Fig. 3). The degree of overlap of the overwinter KDE $75 \%$ contours was significantly larger within the same year than among different years $\left(9 \pm 3 \% \mathrm{SE}, t_{313}=2.8, p<0.005\right.$ ). In 2011 (as well as one bird in 2017 and 2018), individual overwinter ranges were relatively restricted to a limited area of the north coast of Peru, while in 2008 and 2010, overwinter

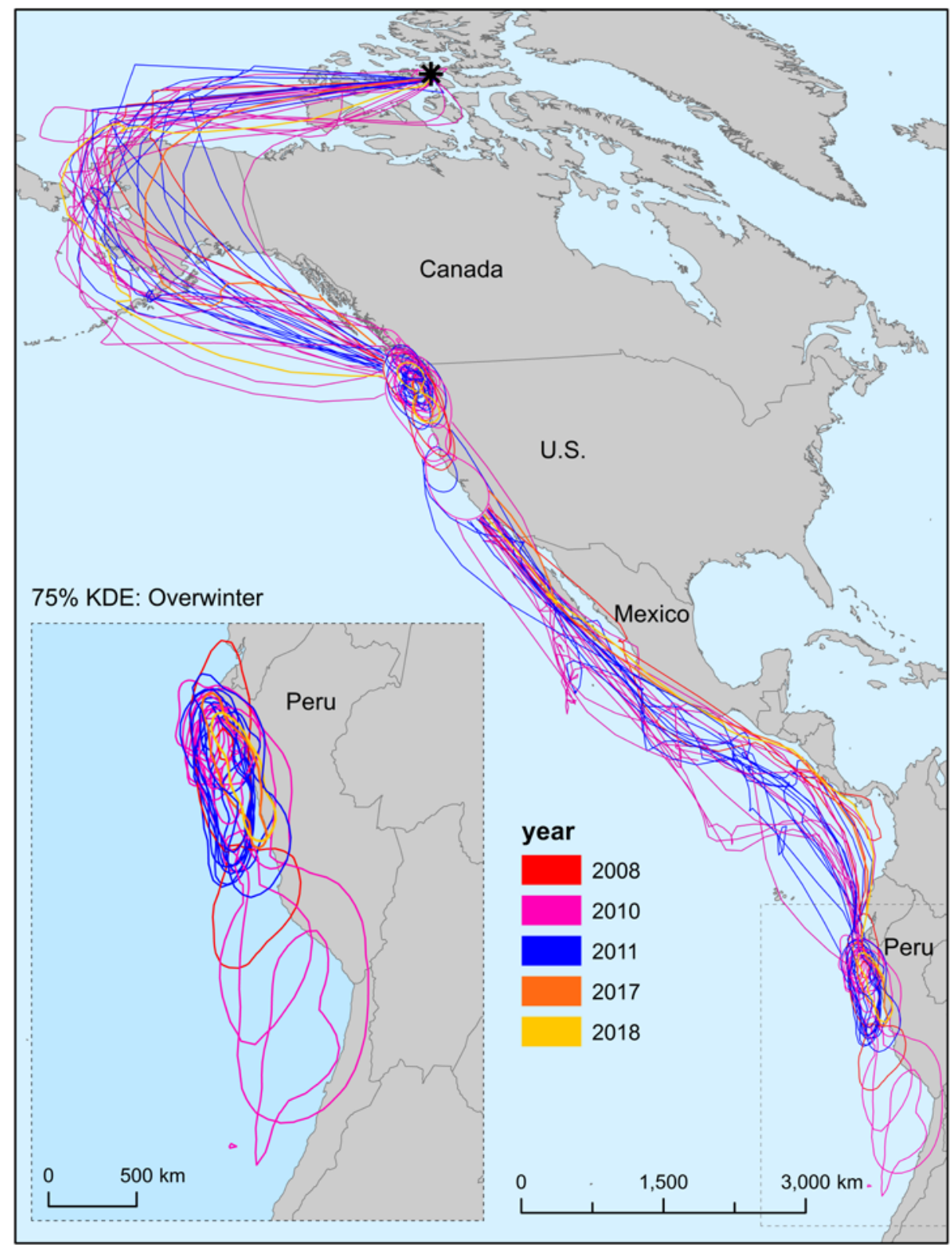

Figure 3: Southbound and overwinter phases of migration by tracking year (as per year of southbound migration initiation). Sample sizes by stage given in Table 1. 
ranges spanned larger areas into the south coast of Peru and the north coast of Chile (Fig. 3).

\subsection{Lack of individual repeatability and sex effects}

Our results indicated only two migratory traits were repeatable within individuals; the arrival date to the staging grounds on southbound migration and the duration of the southbound staging phase were more similar within individuals than among individuals $(R=0.50$, Table 2). We found no significant effects of 'same bird' on any spatial metrics. Moreover, no effects of sex were found on any phenological or spatial metrics.

\section{Discussion}

Our study provides the first detailed account of the complete roundtrip journeys of Sabine's gulls migrating between a high Arctic colony and the overwintering grounds in the Humboldt Current off Peru. We showed that individual Sabine's gulls were generally highly flexible between years in their migratory strategy but made similar decisions to one another in the same years in some phenological and spatial aspects of migration. Regardless of year, all birds showed a repeatable and consistent reliance on staging grounds within the northern California Current System (CCS) from coastal southern B.C. south to California as a key extended stopover site in both directions. Our results suggest that Sabine's gulls are generally able to adjust migratory strategy among years, but that they may be vulnerable to environmental stressors attributable to climate change and other anthropogenic influences during critical, less flexible, stages of the non-breeding period.

Overall, Sabine's gulls exhibited high individual flexibility in most aspects of their migratory behaviour, altering their schedules, routes, number and duration of non-staging stopovers, and fine-scale overwinter range among different tracking years. However, our results suggest that migrating gulls make similar adjustments to migratory strategies within a given year, likely due to being subjected to similar environmental influences throughout migration. In the two years of tracking with sufficient sample sizes for interannual comparison, consistent decision-making among birds was evident in a number of aspects of migration. Some of this variation can be explained by shared experiences on the breeding grounds; in 2010, severe weather conditions during the early chick-rearing period caused widespread chick mortality, resulting in birds departing the colony for

Table 2.: Individual consistency in migration strategy for various migratory traits during southbound migration, staging, and overwinter of Sabine's gulls tracked from the Canadian high Arctic. Individual repeatability ( $R$; or adjusted repeatability for year fixed effects indicated by an asterisk), standard error (SE), p-values (p; not significant (NS)), total sample size of all unique bird-years (i.e. total number of tracks regardless of individual bird ID, $n$ total), sample size of repeatedly tracked individuals (i.e. number of bird-years for individuals tracked in 2 or $3 \mathrm{yrs} /$ number of repeatedly tracked individuals, $n$ repeat).

\begin{tabular}{|c|c|c|c|c|c|}
\hline & $n$ total & $n$ repeat & $\boldsymbol{R}$ & SE & $\mathbf{p}$ \\
\hline southbound migration start date & 32 & $19 / 9$ & $0.08^{*}$ & 0.29 & NS \\
\hline duration southbound pre-staging & 32 & $19 / 9$ & 0.20 & 0.23 & NS \\
\hline distance travelled southbound pre-staging & 32 & $19 / 9$ & 0.21 * & 0.28 & NS \\
\hline number of stopovers southbound pre-staging & 32 & $19 / 9$ & 0.09 & 0.21 & NS \\
\hline number of stopover days southbound pre-staging & 32 & $19 / 9$ & 0.20 & 0.20 & NS \\
\hline southbound staging start date & 32 & $19 / 9$ & 0.50 & 0.23 & $<0.05$ \\
\hline duration southbound staging & 32 & $19 / 9$ & 0.50 & 0.23 & $<0.05$ \\
\hline duration southbound post-staging & 26 & $13 / 6$ & 0 & 0.32 & NS \\
\hline distance travelled southbound post-staging & 26 & $13 / 6$ & 0 & 0.23 & NS \\
\hline number of stopovers southbound post-staging & 26 & $13 / 6$ & 0 & 0.22 & NS \\
\hline number of stopover days southbound post-staging & 26 & $13 / 6$ & 0 & 0.28 & NS \\
\hline overwinter start date & 26 & $13 / 6$ & 0.20 & 0.26 & NS \\
\hline
\end{tabular}


southbound migration on average one week earlier than in the following year [25]. It is possible this additional week allowed birds to take the longer coastal route more common in 2010, rather than the inland route over Alaska more common in 2011. Indeed, the one bird which travelled overland in 2010 departed the colony one week later than the average date for that year. Despite being capable of minimizing the distance and duration of this phase of the migratory journey by taking an overland shortcut, it appears that Sabine's gulls prefer detours through the Bering Sea with frequent stopovers if time allows, much the same as lesser black-backed gulls (Larus fuscus) migrating between the Netherlands and northwest Africa [16].

Intra-annual consistency among birds in migratory strategy was also evident in aspects of the post-staging and overwinter phases of migration. Nonetheless, the arrival and duration of the southbound staging phase was marked by high variation between individuals within the same year, but high repeatability within individuals among years. It follows that shared experiences on the breeding grounds are less likely a contributing factor to similar migratory decisions among birds within the same year regarding the selection of routes following departure of the staging grounds, and the extent of the overwinter range. For example, in 2010, southbound post-staging routes were similarly less direct and less coastal than in 2011, and overwinter ranges were larger and extended farther south. This suggests that these decisions are more likely influenced by ecological conditions in the southern portion of the non-breeding range in a given year rather than being strictly genetically inherited or memory-based $[4,10]$, where movements may be dictated more by the distribution of available resources $[4,8,9]$.

One might expect that a migrating gull would be less reliant on particular routes or reliable stopover sites in comparison to other seabird migrants, instead travelling opportunistically along a flexible migratory route. The generalist foraging and locomotor ability of gulls [16] likely contributed to the striking flexibility, both within (Fig. 1) and between (Fig. 2) individuals, in routes taken in the northern portion of the non-breeding range between the colony and the staging grounds. Southbound migrating Sabine's gulls chose either overland or coastal routes, and were not consistent among tracking years in routes taken. Although individual repeatability could not be evaluated on the northbound phase, high between-individual variation in the routes taken was apparent. The northbound overland routes are particularly remarkable for the mountainous terrain traversed, the distances covered, and the high variation in paths and direction of travel. These northbound routes may allow birds to reach High Arctic breeding sites faster in the spring, and may maximize the likelihood of encountering favourable foraging opportunities in freshwater lakes or early thawing inlets around river mouths in Hudson Bay at a time when large sections of the ocean at northern latitudes remain frozen and inhospitable [14]. The uncommon but regular presence of Sabine's gulls in late May and early June in areas of northern inland Canada, far from known breeding areas, has been previously noted [9], but never conclusively explained. Our confirmation of an overland flight path used by Sabine's gulls travelling between the Pacific and Hudson Bay firmly put these reports into context.

The only other gull known to navigate over the rugged and remote reaches of northern North America is the Thayer's gull (Larus glaucoides thayeri), recently tracked from a colony east of Nasaruvaalik Island [47]. Interestingly, all four tracked Thayer's gulls undertook overland traverses, with none taking coastal routes through the Bering Sea. The tracked Thayer's gulls also remained within the range of the Sabine's gulls' mid-migration staging grounds for the entirety of the non-breeding period, spreading out widely within the CCS, between northern B.C. and south to California. Sabine's gulls, on the other hand, continued south another c. $7,700 \mathrm{~km}$ to reach the restricted overwintering grounds in the Humboldt Current. It is not clear why Sabine's gulls only stop to stage within the northern CCS, rather than winter there with Thayer's gulls, many other gull species (e.g. California gull (Larus californicus) and glaucous-winged gull (Larus glaucescens)), and other diverse seabirds [48, 49]. Similar behaviour was recently reported in roseate terns (Sterna dougallii) migrating from European colonies to winter in the cold-water upwellings of the Guinea Current Large Marine Ecosystem [50]. The tracked terns exhibited staging behaviour within another highly productive upwelling system where other tern species elect to remain for overwinter. Like the roseate tern [50], Sabine's gull must possess unique adaptations to forage within a particular environment during the winter, specialized to the exceptionally localized areas of strong and predictable upwelling off coastal Peru.

Few gull species complete trans-hemispheric migrations to access areas of strong upwelling during overwinter. While long journeys crossing the equator are a fairly common strategy employed by many families of birds, particularly seabirds, that travel between areas of alternating high seasonal productivity $[17,51,52]$, it is relatively rare among Larids [22, 23]. Franklin's gull (Larus pipixcan) is the only other species of gull known to undertake such a migration, travelling between the prairie regions of North America and the same coastal regions of 
Peru [53]. These two surface feeding gulls travel extensive distances to exploit strong upwelling which concentrates large zooplankton and small fish close to the surface for the duration of the non-breeding season. The reliance of Sabine's gulls on areas of high marine productivity has already been shown in the Atlantic population of the species, where birds winter within the Benguela Current off the coast of South Africa [12,13]. The Pacific wintering area within the northern Humboldt Current is similarly an area of high primary productivity producing more forage fish per unit area than any other region in the world's oceans [54, 55], and offers surface foraging seabirds like Sabine's and Franklin's gulls predictable access to exceptionally abundant resources [56]. For these gulls, the risks and demands of a lengthy annual migration are offset by the benefits of targeting areas of extremely high seasonal productivity and likely low predation pressure.

Consistent use of the CCS by all individuals in both migratory directions also emphasizes the importance of this region for migrating Sabine's gulls, at least from our study colony. The CCS spans nearly 3,000 km from Vancouver Island, B.C., to Baja California, Mexico (Fig. 1) $[49,57]$. Similar to the northern Humboldt Current during the overwinter period, the CCS is characterized by strong coastal upwelling conditions, and is known for its extremely high productivity, albeit more dynamic and spatially heterogeneous than the Humboldt $[49,58]$. At the northern end of the CCS, the unique currents and bathymetry create a large semi-permanent cyclonic eddy (the Juan de Fuca Eddy) that is responsible for massive upwelling of cold, deep, nutrient-rich water [58]. This water mixes with freshwater inputs from the Juan de Fuca Strait and spreads over an extensive and shallow bank at the edge of the continental shelf, creating an area of exceptionally favourable conditions for foraging seabirds, whales, and fish [59-61]. In addition to staging in this region, another important stopover area was apparent during a small temporal window in April and May in the northbound pre-staging phase; all birds travelled nearly constantly from the overwintering grounds until reaching the Baja California Peninsula, where stops were made both off the west coast of the peninsula and within the Gulf of California. Again, this region is characterized as the highly productive southern extent of the CCS $[49,62]$. Both the northern and southern extents of the CCS have been identified as Global Marine Important Bird Areas [49]. Our findings lend further support to these designations, and call for future tracking studies from additional colonies to confirm the general importance of these staging and stopover regions to Sabine's gulls migrating through the Pacific.
All tracked Sabine's gulls showed high fidelity to the same staging and overwintering sites but adhered to their own unique staging schedule. This relative individual rigidity in phenology (i.e., highest $R$ value across migratory phases, Table 2) may suggest that gulls could be limited in their ability to adjust to ecological change within the CCS, for example in response to climate-change induced shifts in the timing, distribution, or quantity of food available [11, 57]. In relation to published repeatability values for stop-over timing in long-distance avian migrants [7], Sabine's gulls could be considered less flexible than some relatively short-distance migrants (e.g., black-tailed godwit (Limosa l. limosa); [63]) and more flexible than others with extreme long-distance migrations (e.g., bar-tailed godwit (Limosa lapponica baueri); [64]). However, $R$ values are better used within rather than between studies as a comparative index across consecutive stages to assess relative flexibility and population variation [64]. For Sabine's gulls in our study, significant and relatively high repeatability in both the timing of arrival and duration of the southbound staging phase may indicate that staging phenology is predominantly under learned or genetic control with strong stabilizing selection, while other aspects of migratory strategy are influenced more by environmental conditions [11].

On the other hand, high among-individual variation in timing of arrival and duration of staging may indicate that sufficient variation exists within the population on which selection can act to eventually favour the most advantageous strategies, depending on how rapidly changes to the environment occur [65]. Regardless of timing, fidelity to specific stopover, staging, or wintering sites may be advantageous for long-distance migrants as individuals can rely on inherited or learned preferences based on past conditions $[4,10]$. However, population-level reliance on spatially restricted areas during particular time periods could have consequences for resilience to environmental change [65]. Using a comparison between two migratory shorebird species as a case study, it has been suggested that in general, the number of stopover or staging sites used per individual and among a population, and the time spent among different sites may prove key to explaining migratory populations' resilience to environmental change [65]. In this light, at the population-level, the colony of Sabine's gulls from Nasaruvaalik Island appears vulnerable to deteriorating conditions in the staging or overwintering area that would deem them less favourable or even dangerous due to human impacts [66]. Without a high level of plasticity in areas used, strong individual and population-level consistency in the use of staging and 
wintering areas has the potential to influence population dynamics.

Although Sabine's gulls are not currently threatened in Canada, their high reliance on a few localized areas of high marine productivity within their Pacific non-breeding range are cause for concern. Our data support existing efforts to recognize and protect the importance of some of these sites for seabirds, particularly a series of proposed marine Important Bird Areas (IBAs) within the Peruvian and Chilean Humboldt Current region. Identification of areas as marine IBAs help to determine the relative distribution of important at-sea areas in a global context based on a standardized and internationally agreed upon set of criteria [67]. These designations then provide a useful tool for conservation advocates and policy decision-makers in determining how efforts to implement management plans will contribute to protecting networks of sites that are essential for maintaining the populations and habitats of birds, as well as their associated biodiversity and ecosystem services [67]. Protection and management of the Juan de Fuca Eddy is of particular concern given that the main area of productivity lies directly on the approaches to the Salish Sea, which is the only access to several main seaports on the West Coast. The ongoing (and proposed increased) shipment of petroleum products through this area poses a significant threat to Sabine's gulls as well as other species which rely on this foraging hotspot during both spring and fall migration $[59,68]$. The Juan de Fuca Eddy falls within the Olympic Coast National Marine Sanctuary and the Olympic Continental Shelf marine IBA within U.S. waters $[69,70]$, however similar recognition and protection in Canadian waters does not currently exist [70]. Finally, protective measures or even recognition of marine IBAs in the Baja California Peninsula region are completely lacking [70]. While our study has shown that Sabine's gulls are flexible and able to adjust to environmental change in many aspects of their migration, we also suggest that this species is vulnerable to climate change and other anthropogenic influences during critical stages of the journey.

\section{Acknowledgements}

We thank the numerous field personnel who assisted with gull capture and tagging across the years at Nasaruvaalik Island. All work was conducted under valid permits (CWS Animal Care EC-PN-11-020, CWS Scientific Permit NUNSCI-09-01, Government of Nunavut Wildlife Research Licence WL 2010-042, Nunavut Water Board licence 3BC-
TER0811, Indian and Northern Affairs Land Use Reserve 068H16001, and CWS Banding Permit 10694), and their renewals. Financial support for this project was provided by Environment and Climate Change Canada, Natural Resources Canada (Polar Continental Shelf Program), and Acadia University. SEG was supported by a Weston Family Award in Northern Research Post-Doctoral Fellowship.

\section{References}

[1] Alerstam T., Lindström A., Optimal Bird Migration: The Relative Importance of Time, Energy, and Safety, In: Gwinner, E. (Ed.), Bird Migration, Springer Berlin Heidelberg, 1990, 331-351

[2] Newton I., The ecology of bird migration, Academic Press, London, UK, 2007

[3] Warnock N., Stopping vs. staging: The difference between a hop and a jump, J. Avian Biol., 2010, 41, 621-626

[4] Brown J.M., Loon E.E., Bouten W., Camphuysen K.C.J., Lens L., Müller W., et al., Long-distance migrants vary migratory behaviour as much as short-distance migrants: An individuallevel comparison from a seabird species with diverse migration strategies, J. Anim. Ecol., 2021, 1-13

[5] Gwinner E., Circadian and circannual programmes in avian migration, J. Exp. Biol., 1996, 199, 39-48

[6] Berthold P., Gwinner E., Sonnenschein E., Avian Migration, Springer, Berlin, 2003

[7] Both C., Bijlsma R.G., Ouwehand J., Repeatability in Spring Arrival Dates in Pied Flycatchers Varies among Years and Sexes, Ardea, 2016, 104, 3-21

[8] Alerstam T., Strategies for the transition to breeding in time-selected bird migration, 2006, 94, 347-357

[9] Winkler D.W., Jørgensen C., Both C., Houston A.I., McNamara J.M., Levey D.J., et al., Cues, strategies, and outcomes: how migrating vertebrates track environmental change, Mov. Ecol., 2014, 2, 10

[10] Sutherland W.J., Evidence for Flexibility and Constraint in Migration Systems, J. Av, 1998, 29, 441-446

[11] Pulido F., Widmer M., Are long-distance migrants constrained in their evolutionary response to environmental change? Causes of variation in the timing of autumn migration in a blackcap (S. atricapilla) and two garden warbler (Sylvia borin) populations, Ann. N. Y. Acad. Sci., 2005, 1046, 228-241

[12] Stenhouse I.J., Egevang C., Phillips R.A., Trans-equatorial migration, staging sites and wintering area of Sabine's Gulls Larus sabini in the Atlantic Ocean, Ibis (Lond. 1859)., 2012, 42-51

[13] Davis S.E., Maftei M., Mallory M.L., Migratory Connectivity at High Latitudes: Sabine's Gulls (Xema sabini) from a Colony in the Canadian High Arctic Migrate to Different Oceans, PLoS One, 2016, 11, e0166043

[14] Day R.H., Stenhouse I.J., Gilchrist H.G., Sabine's Gull (Xema sabini), version 1.0., In: Billerman, S.M. (Ed.), Birds of the World, Cornell Lab of Ornithology, Ithaca, NY, USA, 2020

[15] Lambert K., The Migration of Sabine's Gulls, Xema sabini, in the Northwest Atlantic, Can. F. Nat., 1972, 87, 57-60 
[16] Shaffer S.A., Tremblay Y., Weimerskirch H., Scott D., Thompson D.R., Sagar P.M., et al., Migratory shearwaters integrate oceanic resources across the Pacific Ocean in an endless summer, Proc. Natl. Acad. Sci., 2006, 103, 12799-12802

[17] Gilg O., Moe B., Hanssen S.A., Schmidt N.M., Sittler B., Hansen J., et al., Trans-equatorial migration routes, staging sites and wintering areas of a high-arctic avian predator: the long-tailed Skua (Stercorarius longicaudus)., PLoS One, 2013, 8, e64614

[18] McKnight A., Irons D., Allyn A., Sullivan K., Suryan R., Winter dispersal and activity patterns of post-breeding black-legged kittiwakes Rissa tridactyla from Prince William Sound, Alaska, Mar. Ecol. Prog. Ser., 2011, 442, 241-253

[19] Grecian W.J., Williams H.J., Votier S.C., Bearhop S., Cleasby I.R., Grémillet D., et al., Individual spatial consistency and dietary flexibility in the migratory behavior of northern gannets wintering in the northeast Atlantic, Front. Ecol. Evol., 2019, 7, 1-11

[20] Villablanca R., Luna-Jorquera G., Marín V.H., Garthe S., Simeone A., How does a generalist seabird species use its marine habitat? The case of the kelp gull in a coastal upwelling area of the Humboldt Current, ICES J. Mar. Sci., 2007, 64, 1348-1355

[21] Karnovsky N.J., Hobson K.A., Brown Z.W., Hunt G.L., Distribution and Diet of Ivory Gulls (Pagophila eburnea ) in the North Water Polynya, Arctic, 2009, 62, 65-74

[22] Klaassen R.H.G., Ens B.J., Shamoun-Baranes J., Exo K.M., Bairlein F., Migration strategy of a flight generalist, the Lesser Black-backed Gull Larus fuscus, Behav. Ecol., 2012, 23, 58-68

[23] Hatch S.A., Gill V.A., Mulcahy D.M., Migration and wintering areas of glaucous-winged Gulls from south-central Alaska, Condor, 2011, 113, 340-351

[24] Duffy D.C., The foraging ecology of Peruvian seabirds., Auk, 1983, 100, 800-810

[25] Mallory M.L., Boadway K.A., Davis S.E., Maftei M., Breeding biology of Sabine's gull (Xema sabini) in the Canadian high Arctic, Polar Biol., 2012, 35, 335-344

[26] Mallory M.L., Gilbert C.D., Leg-loop harness design for attaching external transmitters to seabirds, Mar. Ornithol., 2008, 36, 183-188

[27] Phillips R., Silk J., Croxall J., Afanasyev V., Briggs D., Accuracy of geolocation estimates for flying seabirds, Mar. Ecol. Prog. Ser., 2004, 266, 265-272

[28] Shaffer S.A., Tremblay Y., Awkerman J. a., Henry R.W., Teo S.L.H., Anderson D.J., et al., Comparison of light- and SST-based geolocation with satellite telemetry in free-ranging albatrosses, Mar. Biol., 2005, 147, 833-843

[29] Shimada T., Limpus C., Jones R., Hazel J., Groom R., Hamann $M$., Sea turtles return home after intentional displacement from coastal foraging areas, Mar. Biol., 2016, 163, 1-14

[30] Hedenström A., Flight Speed of Ross's Gull Rhodostethia rosea and Sabine's Gull, Arctic, 1998, 51, 283-285

[31] Jonsen I.D., Mills Flemming J., Myers, Ransom A., Robust state-space modeling of animal movement, Ecology, 2005, $86,2874-2880$

[32] Jonsen I., Joint estimation over multiple individuals improves behavioural state inference from animal movement data, Sci. Rep., 2016, 6, 20625
[33] Yurkowski D.J., Lunn N.J., Méthé M.A., Hussey N.E., Mallory M.L., Wong S.N.P., et al., Abundance and species diversity hotspots of tracked marine predators across the North American Arctic, Divers. Distrib., 2018, 1-18

[34] Anderson C.M., Gilchrist H.G., Ronconi R.A., Shlepr K.R., Clark D.E., Weseloh D.V.C., et al., Winter home range and habitat selection differs among breeding populations of herring gulls in eastern North America, Mov. Ecol., 2019, 7, 8

[35] Auger-Méthé M., Albertsen C.M., Jonsen I.D., Derocher A.E., Lidgard D.C., Studholme K.R., et al., Spatiotemporal modelling of marine movement data using Template Model Builder (TMB), Mar. Ecol. Prog. Ser., 2017, 565, 237-249

[36] Shaffer S.A., Cockerham S., Warzybok P., Bradley R.W., Jahncke J., Clatterbuck C.A., et al., Population-level plasticity in foraging behavior of western gulls (Larus occidentalis), Mov. Ecol., 2017, 5, 1-13

[37] Fifield D.A., Montevecchi W.A., Garthe S., Gregory J., Kubetzki U., Rail J., et al., Migratory tactics and wintering areas of northern gannets (Morus bassanus) breeding in North America, Ornithol. Monogr., 2014, 79, 1-63

[38] Calenge C., The package "adehabitat" for the R software: A tool for the analysis of space and habitat use by animals, Ecol. Modell., 2006, 197, 516-519

[39] Delord K., Barbraud C., Pinaud D., Ruault S., Patrick S.C., Weimerskirch H., Individual consistency in the non-breeding behavior of a long-distance migrant seabird, the grey petrel Procellaria cinerea, Mar. Ornithol., 2019, 47, 93-103

[40] Müller M.S., Massa B., Phillips R.A., Dell'omo G., Individual consistency and sex differences in migration strategies of scopoli's shearwaters Calonectris diomedea despite year differences, Curr. Zool., 2014, 60, 631-641

[41] Dias M.P., Granadeiro J.P., Catry P., Individual variability in the migratory path and stopovers of a long-distance pelagic migrant, Anim. Behav., 2013, 86, 359-364

[42] Van Bemmelen R., Moe B., Hanssen S.A., Schmidt N.M., Hansen J., Lang J., et al., Flexibility in otherwise consistent non-breeding movements of a long-distance migratory seabird, the long-Tailed skua, Mar. Ecol. Prog. Ser., 2017, 578, 197-211

[43] Bates D., Mächler M., Bolker B.M., Walker S.C., Fitting linear mixed-effects models using Ime4, J. Stat. Softw., 2015, 67

[44] Kuznetsova A., Brockhoff P.B., Christensen R.H.B., ImerTest Package: Tests in Linear Mixed Effects Models , J. Stat. Softw., 2017, 82

[45] Patrick S.C., Bearhop S., Grémillet D., Lescroël A., Grecian W.J., Bodey T.W., et al., Individual differences in searching behaviour and spatial foraging consistency in a central place marine predator, Oikos, 2014, 123, 33-40

[46] Stoffel M.A., Nakagawa S., Schielzeth H., rptR: repeatability estimation and variance decomposition by generalized linear mixed-effects models, Methods Ecol. Evol., 2017, 8, 1639-1644

[47] Gutowsky S.E., Mark Hipfner J., Maftei M., Boyd S., Auger-Méthé M., Yurkowski D.J., et al., First insights into Thayer's gull larus glaucoides thayeri migratory and overwinter patterns along the northeast Pacific coast, Mar. Ornithol., 2020, 48, 9-16

[48] Rintoul C., Langabeer-Schlagenhauf B., Hyrenbach K.D., Morgan K.H., Sydeman W.J., Atlas of California Current 
marine bird and mammal distributions: version 1, Petaluma, California, 2006

[49] Sydeman W.J., Losekoot M., Santora J.A., Thompson S.A., Morgan K.H., Distler T., et al., Hotspots of seabird abundance in the California Current: Implications for Important Bird Areas, Petaluma, CA, 2012

[50] Redfern, C.P.F., Kinchin-Smith, D., Newton, S., Morrison, P., Bolton, M., Piec, D. Upwelling systems in the migration ecology of Roseate Terns (Sterna dougallii) breeding in northwest Europe, Ibis, 2021,163, 549-565'.

[51] Hedd A., Montevecchi W., Otley H., Phillips R., Fifield D., Trans-equatorial migration and habitat use by sooty shearwaters Puffinus griseus from the South Atlantic during the nonbreeding season, Mar. Ecol. Prog. Ser., 2012, 449, 277-290

[52] Mellone U., López-López P., Limiñana R., Piasevoli G., Urios V., The trans-equatorial loop migration system of Eleonora's falcon: differences in migration patterns between age classes, regions and seasons, J. Avian Biol., 2013, 44, 417-426

[53] Burger J., Gochfield M., Franklin's Gull (Leucophaeus pipixcan), version 1.0, Birds of the World, 2020

[54] Daneri G., Dellarossa V., Quiñones R., Jacob B., Montero P., Ulloa O., Primary production and community respiration in the Humboldt Current System off Chile and associated oceanic areas, Mar. Ecol. Prog. Ser., 2000, 197, 41-49

[55] Chavez F.P., Bertrand A., Guevara-Carrasco R., Soler P., Csirke J., The northern Humboldt Current System: Brief history, present status and a view towards the future, Prog. Oceanogr., 2008, 79, 95-105

[56] Weichler T., Garthe S., Luna-Jorquera G., Moraga J., Seabird distribution on the Humboldt Current in northern Chile in relation to hydrography, productivity, and fisheries, ICES J. Mar. Sci., 2004, 61, 148-154

[57] Young L., Suryan R.M., Duffy D., Sydeman W.J., Climate change and seabirds of the California Current and Pacific Islands ecosystems: observed and potential impacts and management implications, US Fish and Wildlife Service, Region 1, 2012

[58] MacFadyen A., Hickey B.M., Cochlan W.P., Influences of the Juan de Fuca Eddy on circulation, nutrients, and phytoplankton production in the northern California Current System, J. Geophys. Res. Ocean., 2008, 113, 1-19
[59] Burger A.E., Hitchcock C.L., Davoren G.K., Spatial aggregations of seabirds and their prey on the continental shelf off SW Vancouver Island, Mar. Ecol. Prog. Ser., 2004, 283, 279-292

[60] Butler R.W., Morgan K.H., Vermeer K., The ecology, status, and conservation of marine and shoreline birds on the west coast of Vancouver Island, Canadian Wildlife Service, 1992

[61] Vermeer K., Morgan K., Smith G.E.J., Hay R., Fall Distribution of Pelagic Birds over the Shelf off SW Vancouver Island, Waterbird Soc., 1989, 12, 207-214

[62] Suryan R.M., Santora J.A., Sydeman W.J., New approach for using remotely sensed chlorophyll a to identify seabird hotspots, Mar. Ecol. Prog. Ser., 2012, 451, 213-225

[63] Lourenço P.M., Kentie R., Schroeder J., Groen N.M., Hooijmeijer J.C.E.W., Piersma T., Repeatable timing of northward departure, arrival and breeding in Black-tailed Godwits Limosa l. limosa, but no domino effects, J. Ornithol., 2011, 152, 1023-1032

[64] Conklin J.R., Battley P.F., Potter M.A., Absolute Consistency: Individual versus Population Variation in Annual-Cycle Schedules of a Long-Distance Migrant Bird, PLoS One, 2013, 8

[65] Lisovski S., Gosbell K., Minton C., Klaassen M., Migration strategy as an indicator of resilience to change in two shorebird species with contrasting population trajectories, J. Anim. Ecol., 2020, 00, 1-10

[66] Robinson R.A., Crick H.Q.P., Learmonth J.A., Maclean I.M.D., Thomas C.D., Bairlein F., et al., Travelling through a warming world: Climate change and migratory species, Endanger. Species Res., 2009, 7, 87-99

[67] Waliczky Z., Fishpool L.D.C., Butchart S.H.M., Thomas D., Heath M.F., Hazin C., et al., Important Bird and Biodiversity Areas (IBAs): their impact on conservation policy, advocacy and action, Bird Conserv. Int., 2019, 29, 199-215

[68] Burger A.E., Effects of the Juan de Fuca Eddy on Densities and Distributions of Seabirds Off Southwest Vancouver Island, British Columbia, Mar. Ornithol., 2003, 122, 113-122

[69] Basta D., Olympic Coast National Marine Sanctuary: final management plan and environmental assessment, Office of National Marine Sanctuaries, National Oceanic and Atmospheric Administration, 2011

[70] Birdlife International, Marine IBA e-atlas, 2021 